\title{
Managing Teamwork: A Key Leadership Practice
}

\author{
Charles D. Kerns \\ Pepperdine University \\ Corperformance, Inc.
}

How leaders manage teamwork impacts team performance and well-being. After a brief review of some relevant literature, a practice oriented framework for managing teamwork is offered and the value of engaging in this process is noted. A proven practical coaching approach and real world application example with an executive are provided to help further operationalize the framework. This approach is offered to help enhance a managerial leader's effectiveness when managing team dynamics and teamwork in workplace settings. Some challenges such as optimizing team behavioral diversity, managing geographically distributed teams, and applying recent developments in neuroscience are considered.

\section{INTRODUCTION}

The linking of resources is an essential managerial leadership competency. ${ }^{1}$ Leaders use linking skills to help coordinate and manage organizational resources, especially people. Managing teamwork is a fundamental practice area within the linking role that leaders play which contributes to leadership and team effectiveness (Kerns \& Ko, 2014).

The concept of managerial performance competencies has been extensively reviewed and numerous taxonomies have been published. These indexes have all included the managerial leader practice area of teamwork (Tett, Guterman, Bleier \& Murphy, 2000; Yulk, 2012; Kerns \& Ko, 2014). While the labels and language used to refer to teams and teamwork practices studied within these taxonomies varies, the positioning of managerial leadership teamwork skills as a key practice area is consistent across these more academically oriented studies.

Other targeted frameworks have been offered that focus more directly on team leadership (Hackman, 2002; Fleishman, Mumford, Zaccaro, Levin, Korotkin \& Hein, 1991). Different domains that are associated with team effectiveness such as team, team leadership and overall leadership have been reviewed (Morgeson, De Rue, \& Karam, 2010). Also, key distinctions between team leadership and traditional approaches to leadership have been offered in the extant literature (Zaccaro, Rittman, \& Marks, 2001; Kozlowski, Watola, Jensen, Kim, \& Botero, 2009). Team leaders, for example, need to focus on both the individual and team levels of functioning when facilitating the development and performance of teams.

Applied research has also underscored the importance of teamwork skills in enhancing leadership effectiveness and emergence. For example, the fostering and managing of workplace engagement to offset the costs of disengagement is enhanced by the teamwork skills of organizational leaders (Kerns, 2014). Leaders who have teamwork skills can help their organizations more effectively formulate and execute strategies to create and sustain cultures of employee engagement which will help provide for a competitive 
advantage and successful positioning of enterprises in the global marketplace (Mathieu, Maynard, Rapp \& Gibson, 2008). Beyond the positive impacts that the effective management of teamwork can have on employee engagement, there is evidence that this managerial leadership practice can also boost team wellbeing and performance (Oades \& Dulagil, 2017). Interestingly, reciprocal relations exist between teamlevel well-being and individual well-being. For example, teams with high morale allow strengths to emerge which encourages individual members to engage and flourish as part of a positive team (Peterson, Park, \& Seligman, 2005; Peterson \& Seligman, 2004; Bryant \& Veroff, 2006). Richardson and West (2010) offer that team engagement and well-being evolve through the effective allocation of individual team member resources in combination with processes to achieve desired outcomes.

As used in this article, the practice of managing teamwork in the context of managerial leadership is defined as follows:

The coordinated linking of talent, effort, and resources among a defined set of people around a shared purpose, common goals and values to enhance performance and well-being for stakeholders.

A managerial leader can benefit by having a practice-oriented framework and approach to managing teamwork. In alignment with calls for theory and conceptualization in behavioral science to include facts and observations gleaned from the real-world of practice, the author has developed an approach to enhance managerial leadership effectiveness by managing teamwork (Locke, 2007; Locke \& Cooper, 2000). While innumerable books, articles, seminars, classes and coaching proliferate focusing on improvement of any number of distinct components of teamwork, there is little available that integrates the key components of managing teamwork into one integrated approach.

The intent of this article is to offer one integrated practice-oriented framework and application example to help seasoned professionals and emerging leaders enhance their effectiveness at managing teamwork. The current work may also serve as a springboard for practitioners, teachers and applied researchers to help those they serve become increasingly effective in managing teamwork.

\section{PRACTICE - ORIENTED FRAMEWORK}

Substantial opportunities exist for practitioners, researchers and teachers to utilize knowledge about teams, team dynamics, and teamwork skills. The framework offered here applies this knowledge by building upon observations and experience in working with a broad range of managerial leaders across diverse settings. Based on fieldwork, applied research and consulting, together with relevant literature reviews, over the past 35 years the author has made the following observations about teams and teamwork applied to organizational leaders:

- The topics of team leadership, teams and teamwork are pervasive in workplace settings. While many of the skills associated with the concept of teamwork have been studied separately, in practice they are highly interactive and need to be considered in a more integrated way.

- Managing teamwork is considered a key managerial leadership practice contained within a broader competency relating to the linking of resources (Kerns \& Ko,2014).

- There are no widely accepted theoretical models/frameworks that fully integrate the skills that are fundamental to the practice of managing teamwork. This situation leaves the practitioner without an integrated evidence-based approach or practical guidance in his or her work with teams (Shuffler, Burke, Kramer \& Salas, 2013).

- The practice of managing teams is a dynamic process which includes understanding taskprocess roles, context and outcomes (Marks, Mathieu, \& Zaccaro, 2001).

- Organizational leaders can better assess how well they are doing in practicing managing teamwork by using practical assessment tools to measure their effectiveness (Ohland, Loughry, Woehr, Bullard, Felder, Finelli, Layton, Pomeranz \& Schmucker, 2012).

- Interdependency, shared purpose, common goals, and related processes are essential to team effectiveness (Morgeson, DeRue, \& Karam, 2010). 
- Individuals and teams need a sufficient level of well-being to optimize performance (Kerns, 2018). There are reciprocal relationships between individual well-being and team-level wellbeing (Peterson, Park, \& Seligman, 2005).

- Team leadership is integral to team functioning, development and performance (Hackman \& Wageman, 2005; Zaccaro, Rittman \& Marks, 2001; Delarue, Van Hootegem, Procter \& Burridge, 2008). Training and coaching leaders can also improve their performance and their team's effectiveness (Santos, Caetano, \& Tavares, 2015).

- Individual differences contribute to behavioral diversity within teams which can offer both challenges and opportunities in managing teamwork (Colbert, Barrick \& Bradley, 2014; Kerns, 2015).

- The emerging findings from the field of neuroscience likely hold promise for managing teamwork (Molenberghs, Prochilo, Steffens, Zacher \& Haslam, 2017; Ashkanasy, Becker \& Waldman, 2014; Dimitriadis \& Psychogios, 2016; Fabritius \& Hagemann, 2017).

- Geographically distributed teams present potential challenges to team communication and interactions (Van Quaquebeke \& Felps, 2018; Kacmar, Witt, Zivnuska \& Gully, 2003).

- Effectively managing teamwork in the knowledge economy can lead to wiser judgements, choices and team value-added wisdom contributions (Shoemaker \& Tetlock, 2017; Kunzmann \& Thomas, 2015).

Based on the above observations and study of the topic of managing teamwork with the perspectives of a business consultant/industrial-organizational psychologist, applied behavioral science professor/ scholar and practitioner who has served on the workplace firing line, over the years the author has developed an integrated framework to help emerging and seasoned managerial leaders enhance their management of teams. ${ }^{2}$ This framework of managing teamwork, depicted below in Figure 1, has been applied in many settings including work organizations, executive education classrooms and applied research projects. The model is practitioner friendly and conceptually tied to relevant literature relating to the study of leadership, group dynamics and teamwork. 


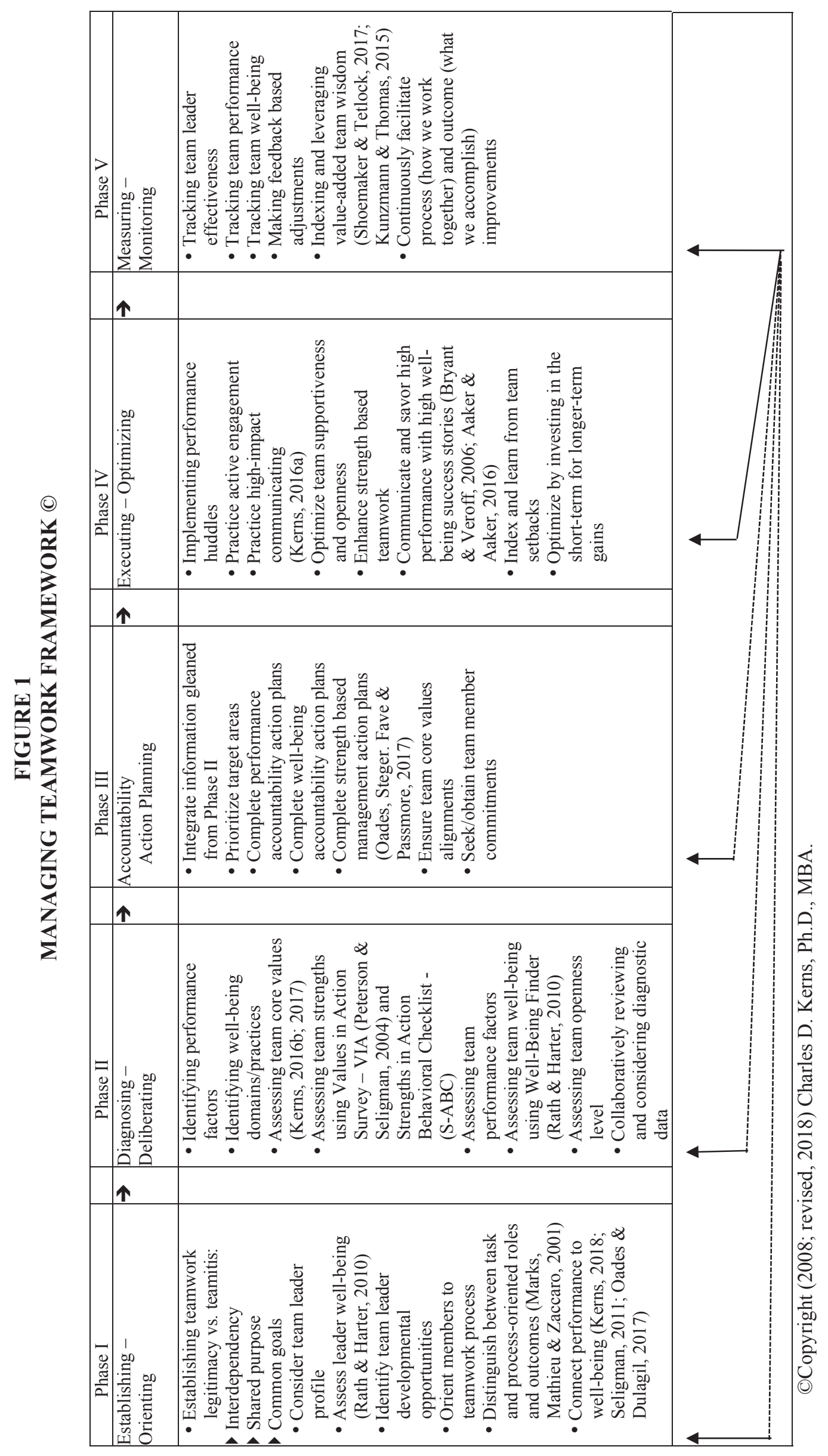

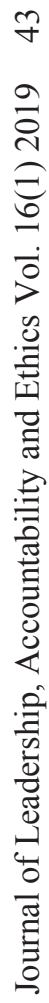


Teamwork cannot be effective if the leader focuses on fewer than all of the components in his or her work; the components need to be integrated into one coherent framework. This proven five phased framework integrates key action areas to more fully examine the process of managing teamwork: establishing-orienting, diagnosing-deliberating, accountability action planning, executing-optimizing, and measuring-monitoring. The framework presented in Figure 1 addresses the need for a holistic, integrated, practical approach to effective teamwork management.

In the framework, the five phases are presented in the chronological order of the most basic teamwork management; however, the components are inter-related and in practice are dynamic and interactive. The discussion below describes the components and the interplay among them.

\section{Phase I: Establishing - Orienting}

Establishing a legitimate basis for teamwork and team building is essential. First, there needs to be real and perceived interdependency among the team members. These interdependencies come together through teamwork to produce desired outcomes beyond what could be achieved by individuals working independently. Second, these interdependencies are further leveraged when a team leader facilitates the formulation of a shared purpose. The third element to legitimizing the basis for teamwork is the establishment of a set of common goals. When these three elements are present there is a basis for investing in teamwork and team building. Without the presence of interdependencies among team member functions, a shared purpose, and a set of common goals, the team leader may be practicing "teamitis" - a term coined by the author to indicate when team leadership attempts to manage teamwork and/or team build without establishing a legitimate basis to do so.

It is also important during Phase I that the leader orients team members to some key teamwork concepts which include distinguishing between task oriented roles and process oriented work. The leader stresses the need for teamwork to reflect a balanced focus between what tasks need to be accomplished (task roles) and how the team works together (process roles) to get the work done. Too much task orientation without enough attention to the process, gets the work done but does not likely build sufficient levels of cohesion among team members. It is equally important that the leader helps team members recognize the relationship between performance and well-being at the individual and team level. This orientation includes having the leader assess his/her well-being and connect it to team performance. For example, he/she can describe how having common goals can enhance both performance and well-being by focusing on accomplishment which has been found to positively influence both individual and team performance and well-being (Seligman, 2011; Kerns, 2018).

\section{Phase II: Diagnosing - Deliberating}

Once the foundational basis for teamwork has been established and the team is oriented to key processes, it is important that the team leader facilitates the team in assessing and deliberating around the findings in several key areas. Performance factors, well-being practices, core values and strengths need to be identified and assessed. This diagnostic process and the associated collaborative deliberations typically lead to greater team openness and supportiveness. Phase II offers an opportunity for a team to determine its individual and collective resource pool of talents. When effectively facilitated, team members emerge with a clearer and more cohesive understanding of who they are and what they stand for as team. Core values, strengths, performance and wellbeing become more present and connected to their functioning as a team. Diagnosing and deliberating around the assessment findings also helps a team actively engage in accountability action planning.

\section{Phase III: Accountability Action Planning}

With the assessment findings and related deliberations in hand, the team leader can facilitate the integration of this information into key learning take aways. These observations can help organize and prioritize areas to target for action planning. Action plans need to address performance factors and wellbeing practices as well as team strengths as a resource. They also need to ensure that team core values are aligned within the team and with other stakeholders. Member buy-in is accomplished, in part, by having 
the team leader inquire and index the level of commitment that is present among team members for executing and striving to optimize the action plans.

\section{Phase IV: Executing - Optimizing}

As an extension of the accountability action planning teamwork in Phase III, performance huddles are featured as part of executing and optimizing these programs of action. Performance huddles serve as accountability forums in which the team leader regularly meets with his/her team to review progress on achieving mutually agreed upon actions, assess impacts of these actions and offer next step actions. This huddling process finds the leader listening, encouraging and holding the team and specific members accountable for what they committed to do. They also present opportunities to practice active engagement and high-impact communicating (Kerns, 2016a).

As team members work together, the leader facilitates the communication and savoring of success stories while also making time to reflect on and learn from team setbacks. Throughout this phase the leader is modeling openness and supportiveness and encouraging team members to display these behaviors in their interactions. The team members are also encouraged to apply their strengths to teamwork. The value of performance optimization is also recognized and supported during this phase. It is understood that attempting to be highly efficient in all matters (not optimizing) may cause the team to miss opportunities to invest in the short term for potentially longer-term gains (i.e. this may happen when the team does not engage in short-term inefficiencies for potential longer-term gains). Investments in optimization activities/projects are measured and monitored during Phase V.

\section{Phase V: Measuring - Monitoring}

Results management is a key phase in the managing teamwork framework. Measuring and monitoring how the team leader is doing in his/her leadership role and how well the team is doing (team effectiveness) is vital to the five phase approach. It is during this phase that the leader's effectiveness is tracked against a performance profile, and team performance and well-being are measured against the mutually agreed accountability action plans and priority targets set in Phase III Accountability Action Planning. The measuring and monitoring of outcomes is not a one-time event but an ongoing interactive process characterized by feedback, adaptation and continuous improvement. It is hoped that over time team leaders and their teams index and leverage value-added wisdom gained from making wise choices and decisions (Shoemaker \& Tetlock, 2017).

\section{THE VALUE OF MANAGING TEAMWORK}

The process of effectively and systematically managing teamwork provides a variety of benefits. There is evidence that team leadership enhances team effectiveness (Hu \& Liden, 2011; Colbert, Barrick \& Bradley, 2014; Rickards, Chen \& Moger, 2001). Delarue, Hootegem, Procter and Burridge (2008) reviewed a variety of performance outcomes across 31 studies showing that teamwork improves organizational performance. These investigators identified the following four areas that relate to teamwork and organizational performance:

- Attitudinal outcomes

- Behavioral outcomes

- Operational outcomes

- Financial outcomes

Given that teamwork can have a positive impact on performance it seems valuable for leaders of teams to be effective in managing teamwork. These efforts can be advanced when leaders have practice-oriented frameworks and tools at their disposal to help guide their work.

Further studies have found that training and coaching of team leaders can improve their effectiveness in managing teamwork (Santos, Caetano, \& Tavares, 2015; Hackman \& Wageman, 2005). Training and development efforts are especially important given the potential impact that team leaders can have on performance. Improving efficacy in managing teamwork is a valuable developmental goal for leaders. 
Systematic approaches to managing teamwork such as the one offered in this article can positively impact this leadership practice. These efforts can benefit teams, team leaders, and organizations.

Managing teamwork helps leverage and draw upon organizational resources, especially people. When people can bring their personal resource pool of talents to teams they benefit individually and the collective is likely strengthened (Richardson \& West, 2010). In understanding the talent pool of prospective team members, team leaders have the opportunity to bring together and manage behavioral diversity within teams. While behavioral diversity can be challenging for leaders to manage, it can be a valuable resource that offers fresh perspectives and different ways to approach challenges. Behavioral diversity is also reflected in such areas as personality, strengths and work style preferences of team members.

Systematically managing teamwork affords the opportunity to establish individual and collective accountabilities for action planning and execution. When working well, the management of teams allows the team leader to facilitate a performance oriented team infrastructure that helps members come together around a shared purpose and common goals to accomplish important work in an interdependent way. In this type of team culture, individuals come to see the process gains and outcomes that teamwork yields. When managed effectively, teams and teamwork can be a source of work satisfaction and career well-being (Rath \& Harter, 2010).

Beyond these observations, when a leader effectively manages teamwork, the quality of relationships at work are likely enhanced both inside and outside his/her team. Proactive actions on the part of team leaders that create and sustain high-quality connections matter (Dutton, 2014). These relationship enhancing actions help enable task completion, build trust and likely increase discretionary effort among team members. More broadly, managing teamwork effectively enhances well-being and allows individuals, teams and organizations to flourish (Roffey, 2017). Kerns (2018) offers leaders evidence based practices for enhancing well-being which have practical utility for managing teamwork and include fostering engagement, meaningfulness, and the use of strengths at work.

\section{A SEVEN STEP APPROACH}

To offer additional practical utility to the concept of managing teamwork, the following seven step approach provides a specific adaptation of the Managing Teamwork Framework shown in Figure 1. This approach, developed in the context of executive coaching to help leaders focus on the practice of managing teamwork, offers a way for team leaders to facilitate their teams to become higher performing with higher well-being.

\section{Step 1: Positioning Managing Teamwork}

The first step in the seven step approach is intended to establish the legitimacy of the need for teamwork and perhaps team building. The coach should orient the team leader to this systematic process while informing him/her of the value in using this approach. It is important that the participant being coached is committed to using the approach with his/her team.

\section{Step 2: Assessing and Collaborative Learning}

Using appropriate assessment tools, which may include those previously noted in connection with the Managing Teamwork Framework (e.g. Well-Being Finder, Values in Action Survey and Strengths in Action Behavioral Checklist), the executive coach will facilitate the client in identifying and assessing team performance factors, well-being, core values and strengths. The coach will also support the client in facilitating collaborative discussions with his/her team regarding the assessment findings and how to best utilize this diagnostic data and convert this information to programs of action.

\section{Step 3: Prioritizing and Targeting}

The executive coach next prepares the client to utilize an importance-influence matrix with his/her team to prioritize and target areas for action planning. It also provides the opportunity for assigning accountabilities to the team as well as to specific team members during Step 4. 


\section{Step 4: Accountable Action Planning}

With key action areas targeted and prioritized the client can proceed with developing specific accountability based action plans in collaboration with his/her team. Prior to engaging in the actual action planning sessions, the coach typically meets with the client to discuss how to best ensure that his/her team is aligned with the action plans and committed to executing them.

\section{Step 5: Team Performance Huddling and Action Learning}

In this step, the executive coach trains the client on conducting team performance huddles to facilitate action learning. This training includes reviewing the purpose and format of the huddle process while the coach models for the client how to facilitate a team performance huddle. Subsequently, the coach attends the client's initial team performance huddle and others as needed and mutually agreed by the coach and client. A key component of the performance huddle system is the specification of action learning items that individual team members and/or the team as a whole commit to doing between huddle sessions.

\section{Step 6: Team Story Telling}

The client is coached in how to help his/her team develop and strategically communicate impactful stories to key stakeholders. These stories are intended to bring attention to key actions that the team has completed and/or is in the process of completing. The content of the stories typically index successful and uplifting experiences that the team leader and team find worth savoring (Bryant \& Veroff, 2006). A key reason for team story telling is to have key stakeholders become more aware of and engage, as appropriate and needed, in what the team is doing. These stories also help the client and his/her team proactively communicate with interested parties and bring positive attention to their teamwork. Story telling is an effective way for leaders and their teams to communicate to key stakeholders (Aaker \& Aaker, 2016; Auvinen, Aaltio \& Blomqvist, 2013).

\section{Step 7: Indexing and Leveraging Outcomes}

In this final step the executive coach works with the client to index and leverage his/her successes in managing his/her team. To account for team accomplishments, the client will answer the question, "how are we doing as a team?" Team effectiveness is indexed on both outcome measures and process metrics. Outcomes measures relate to more business/organizational metrics while process measures reflect how well the team is working together. (This step, in practice, is happening on an ongoing basis as the team leader receives real time feedback on his/her performance and that of his/her team.)

\section{APPLYING THE STEPWISE APPROACH - AN EXAMPLE}

To demonstrate and assist in putting the stepwise approach into practice, the following example is provided. ${ }^{3}$ George is the Director of Supply Chain Operations within a division in a global organization. He has five key reports and he reports to the Chief Operating Officer (COO) within the division. In the context of executive coaching, what follows is the adaptation/customization of the seven step approach to enable George to manage teamwork within his division. This program was part of a larger performance and well-being enhancement program within George's division.

\section{Step 1: Positioning Managing Teamwork}

The executive coach established with George that there was a legitimate basis for engaging in this seven step approach. This was accomplished by having him rate (using a 5-point Likert scale) and then discuss with the executive coach the extent to which his team has interdependency, a shared purpose and common goals. George rated interdependency high among his team members but disclosed that he had not facilitated his team in documenting a clear shared purpose and set of common goals.

The executive coach next oriented George to the overall stepwise approach and noted a number of benefits that this process held for him. Benefits that were reviewed included: 
- George would be able to consider his effectiveness as a team leader and identify potential areas for growth and development relating to managing teamwork.

- With coaching, he could learn to apply this approach with his five key reports.

- George would have a more professional way of assessing his team's effectiveness.

- This approach would help him more systematically manage his team for higher performance with higher well-being.

- He would also be better able to hold himself and his team accountable for following up on action plans and tracking outcomes.

After reviewing each of the program steps, George was probed for his level of commitment to engaging in this program. His level of commitment was high and he was especially eager to engage in both the assessment and performance huddling processes.

\section{Step 2: Assessing and Collaborative Learning}

Using a personalized set of assessment tools, George was facilitated in helping his team complete these assessments. George and his team members each completed the Values in Action Survey (VIA) on-line, the Strengths in Action Checklist (S-ABC), another core values checklist, and the Well-Being Finder. Also, George and his team assessed the following six team performance factors:

- Direction

- Innovation

- Communication

- Internal Customer Satisfaction

- Conflict Management

- Well-Being

Following the assessment of these six factors, George and his team discussed ways that they could improve their functioning in each of the six areas.

\section{Step 3: Prioritizing and Targeting}

Using the importance-influence matrix, with some coaching support George and his team identified the Internal Customer Satisfaction and Well-Being factors as target areas for action planning. The factors of Communication and Conflict Management were strongly considered for targeting but through collaborative discussion the team decided to focus on the two areas of most importance that they could most influence and track (i.e. Internal Customer Satisfaction and Well-Being). Through collaborative discussion these two areas were also identified as being closely aligned with the team's core values of people, accountability and results.

\section{Step 4: Accountable Action Planning}

As part of this step, the executive coach held a one-on-one session with George in which they agreed to have each team member review the action plans after they were collaboratively developed for each of the two team performance factors and rate them (using a 10 point Likert scale) for their level of support for the action plans and their level of commitment to moving forward with the implementation of the plans. Subsequent to this one-on-one meeting, George and the executive coach met in a series of action planning sessions to identify actions and accountabilities. The key actions and accountabilities emerging from these action planning sessions included the following:

1. George and his team members would assess and track their well-being on a monthly basis using a form that was adapted for their use by the executive coach.

2. George and his team members would assess the performance of each functional area represented on the team for the extent to which they were helpful, responsive and respectful in their interactions with one another on a monthly basis. A simple on-line rating system was implemented for measuring Internal Customer Satisfaction on helpfulness, responsiveness and respectfulness (Kerns, 2000). 
3. Each member of the team also agreed to attend a brief (10-15 minutes) monthly performance huddle/accountability forum to review the team's well-being and internal customer satisfaction performance.

4. George agreed to collect and aggregate the data on well-being and internal customer satisfaction for review at each of the performance huddles. He also committed to facilitating his team in generating action items on a monthly basis between performance huddle sessions.

5. The team mutually agreed to commit to this action program for at least five consecutive quarters.

\section{Step 5: Team Performance Huddling and Action Learning}

The executive coach provided one-on-one coaching for George as he prepared to conduct his initial performance huddle with his team. This training session went well and he was able to conduct subsequent huddles effectively. One challenge for George was ensuringthat he asked enough open-ended questions to get his team to generate ideas on how to drive well-being and internal customer satisfaction. By asking more open-ended questions rather than making declarative statements, George was able to foster more active engagement from his team in the action planning process. George reported that he and his team were able to consistently generate specific and useful action learning items at each of their monthly performance huddles.

\section{Step 6: Team Storytelling}

The executive coach conducted several experiential/hands on sessions on storytelling with George and his team. Subsequently, his team held several storytelling sessions with key internal stakeholder groups within their division and one session with a corporate group. All of these sessions had high impact and brought positive attention to the work the team was doing to enhance internal customer satisfaction and well-being.

\section{Step 7: Indexing and Leveraging Outcomes}

On an ongoing basis the executive coach met with George to track the team's well-being and its performance relating to the internal customer satisfaction factor. Over the course of five quarters both of these outcomes improved. Individual team members reported that their well-being improved and that they experienced positive spillover effects in other areas of their lives outside of work. Also, the helpfulness, responsiveness and respectfulness ratings within the team and with functional areas outside the team improved. It was interesting to observe that the content of many of their success stories (Step 6) was based on the action learning items that were generated during the team's monthly performance huddles and which were subsequently successfully executed.

\section{SOME CHALLENGES}

The implementation of the managing teamwork approach presents some challenging issues. There is a need to help team leaders recognize and manage behavioral diversity within their teams. Without this skill those charged with leading teams will likely not be able to optimize the unique individual differences that are present in most teams. In particular, different personalities, conflict management styles and approaches to learning can be assets or liabilities to teamwork depending how the leader manages them. Organizational leaders are challenged to find practical and cost effective ways to help their team leaders recognize, manage and optimize the diverse behavioral profiles that are present in workplace teams.

Another challenge for managing teamwork is the need for team leaders to become familiar with and draw from the emerging work in neuroscience applicable to managing teamwork. Fabritius and Hagemann (2017), for example, suggest that working in a team which lacks or does not leverage behavioral diversity can cause our brains to become complacent which may dampen innovative thinking and curiosity. They also indicate that teams of the future will be lead by individuals who can create brain-friendly work environments. These team leaders will help create and sustain team atmospheres which recognize the value 
of exercise, nutrition and sleep as assets in managing stress. They will find ways to encourage and support teamwork practices that are aligned with this perspective. Also, team leaders with an awareness of how the biochemistry of the brain connects with concepts like fairness will likely integrate these understandings into their recognition delivery practices. Fairness, for example, triggers the release of oxytocin in the brain which has been shown to influence collaborative behavior which is important to teamwork (Brann, 2015). Another challenge is to encourage organizations and team leaders to see teams as a resource for thought leadership (Kerns, 2019). Thought leadership processes can be nested in teams and lead by team leaders to help build team as well as organizational wisdom (Schoemaker \& Tetlock, 2017; Chuang, Jackson \& Jiang, 2016). Part of this challenge will concern how to operationally define and measure wisdom (Ragab \& Arisha, 2013; Walsh, 2015). Schoemaker and Tetlock (2017) offer some interesting ways to blend technology enabled insights with softer human factors such as judgement, reasoning and intuition. Team leaders are challenged to more fully consider how to index wisdom based performance and account for wise value added outcomes that are produced by their teams.

The presence of geographically distributed teams creates challenges for team leaders, as highlighted by the recent work of Van Quaquebeke and Felps (2018). They contend that physical distance leads to less respectful inquiry between leaders and followers. More specifically, distance creates less opportunity for interactions and limits the amount of times leaders can exercise their need for relatedness with their team members. However, physical distance between leaders and team members is commonplace in workplace settings (Antonakis \& Atwater, 2002). This distance requires leaders and followers to exert more effort and deliberation to schedule time to communicate (Cascio \& Shurygailo, 2003). Physical distance between team members typically results in the reliance on email exchanges and other less warm relationship enhancing modes of communicating which increase the chances for interpersonal conflicts to surface (Friedman \& Currall, 2003). In any event, teamwork and team dynamics are likely negatively impacted by distance. This circumstance, while common, especially in global businesses, presents an ongoing challenge for team leaders to address and manage.

Finally, team leaders are challenged to become role models of well-being for their teams. Increasingly, leader well-being is being shown to impact the well-being of employees as well as other stakeholders (Kerns, 2018). There is also growing evidence of the negative impacts and costs that lower levels of wellbeing have on workforces across the world. Alarmingly, the base rate for ineffective, incompetent and/or abusive bosses remains high (Kaiser, LeBreton \& Hogan, 2015). Team leaders need to address the challenge of becoming well-being role models by assessing, managing and optimizing their own well-being. The power of positive performance role modeling is well-established (Bandura, 1977, 1986). Team leaders need to face this challenge by applying well-being evidence-based enhancing practices to their work with their teams. These practices include fostering engagement, displaying positivity and connecting work to meaningfulness (Kerns, 2018; Oades \& Dulagil, 2017).

\section{SUMMARY COMMENTS}

Practical approaches to managing teamwork can be of benefit to organizational leaders. Effectively managing teamwork positively impacts individual team members, the team and the organization. There is a need for applied researchers and practitioners to continue to find ways to help leaders effectively manage teamwork and team dynamics. As this work unfolds there is a need to recognize and manage the behavioral diversity found within teams and look to integrate relevant findings from neuroscience to help support these efforts. Also, team leaders and their organizations are challenged to see teams as a resource and process for thought leadership and to recognize wisdom as an outcome produced by effective teamwork. Team leaders are further challenged to find ways to manage geographically disbursed teams. There is a challenge for leaders to become positive role models for well-being for the teams they lead. All of these efforts will help advance managerial leaders as they strive to effectively contribute to enhancing high-performance with high well-being. 


\section{ENDNOTES}

1. A debate comparing and contrasting management and leadership has occurred over more than three decades. In this article the terms managerial leadership, management, leadership, leader, and manager are used synonymously.

2. This system of managerial leadership strives to provide practitioners, applied researchers and teachers with an integrated approach to viewing and understanding leadership. The system brings together several streams of leadership study and research that have been offered over the past 100 years. A core dimension in this model relates to a leader's competencies. As part of this dimension a better understanding and management of the linker role and the associated practice of managing teamwork can help advance the practice, study and teaching of leadership. It is beyond the scope of the current presentation to review and discuss the other system dimensions and their related practices.

3. This example is drawn from the author's work as an executive coach/trusted advisor with a key executive. For confidentiality purposes, identifying information has been changed.

\section{REFERENCES}

Aaker, D., \& Aaker, J. (2016). What are your signature stories? California Management Review, 58(3), 49-68.

Antonakis, J., \& Atwater, L.E. (2002). Leader distance A review and a proposed theory. Leadership Quarterly, 13, 673-704.

Ashkanasy, N.M., Becker, W.J., \& Waldman, D.A. (2014). Neuroscience and organizational behavior: Avoiding both neuro-euphoria and neuro-phobia. Journal of Organizational Behavior, 35, 909919.

Auvinen, T., Aaltio, I., \& Blomqvist, K. (2013). Constructing leadership by storytelling - the meaning of trust and narratives. Leadership and Organization Development Journal, 34(6), 496-514.

Bandura, A. (1977). Social learning theory. Englewood Cliffs, NJ: Prentice Hall.

Bandura, A. (1986). Social foundations of thoughts \& actions: A social cognitive theory. Englewood Cliffs, NJ: Prentice Hall.

Brann, A. (2015). Neuroscience for coaches: How to use the latest insights for the benefit of your clients. London, UK: Kogan Page.

Bryant, F.B. \& Veroff, J. (2006). The process of savoring: A new model of positive experience. Mahwah, NJ: Erlbaum.

Cascio, W.F., \& Shurygailo, S. (2003). E-leadership and virtual teams. Organizational Dynamics, 31, 362-376.

Chuang, C., Jackson, S.E., Jiang, Y. (2016). Can knowledge-intensive teamwork be managed? Examining the roles of HRM systems, leadership, and tacit knowledge. Journal of Management, 42(2), 524554.

Colbert, A.E., Barrick, M.R., Bradley, R.H. (2014). Personality and leadership composition in top management teams: Implications for organizational effectiveness. Personality Psychology, 67, 351-387.

Delarue, A., Van Hootegem, G., Procter, S. \& Burridge, M. (2008). Teamworking and organizational performance: A review of survey-based research. International Journal of Management Reviews, $10(2), 127-148$.

Dimitriadis, N., \& Psychogios, A. (2016). Neuroscience for leaders: A brain-adaptive leadership approach. Philadelphia, PA: Kogan Page.

Dutton, J.E. (2014). Build high quality connections. In J.E. Dutton \& G.M. Spreitzer (Eds.), How to be a positive leader: Small actions big impacts (p. 11-21). San Francisco, AC: Berrett-Koehler.

Fabritius, F., \& Hagemann, H.W. (2017). The leading brain: Powerful science-based strategies for achieving peak performance. New York, NY: TarcherPerigee.

Fleishman, E.A., Mumford, M.D., Zaccaro, S.J., Levin, K.Y., Korotkin, A.L., \& Hein, M.B. (1991). Taxonomic efforts in the description of leader behavior: A synthesis and functional interpretation. The Leadership Quarterly, 2(4), 245-2873. 
Friedman, R.A., \& Currall, S.S. (2003). E-mail escalation: Dispute exacerbating elements of e-mail communication. Human Relations, 56, 1325-1347.

Hackman, J.R. \& Wageman, R. (2005). A theory of team coaching. Academy of Management Review, $30(2), 269-287$.

Hackman, J.R. (2002). Leading teams: Setting the stage for great performances, Boston: Harvard Business School Press.

Hu, J. \& Liden, R.C. 2011. Antecedents of team potency and team effectiveness: An examination of goal and process clarity and servant leadership. Journal of Applied Psychology, 96(4), 851-862.

Kacmar, K.M., Witt, L.A., Zivnuska, S., \& Gully, S.M. (2003). The interactive effect of leader-member exchange and communication frequency on performance ratings. Journal of Applied Psychology, 88(4), 764-772.

Kaiser, R.B., LeBreton, J.M. \& Hogan, J. (2015). The dark side of personality and extreme leadership. Applied Psychology, 64(1), 55-92.

Kerns, C.D. \& Ko, K. (2014). Managerial leadership competencies: A practice-oriented action role framework. International Leadership Journal, 6(1), 82-99.

Kerns, C.D. (2000). Serving each other on the inside: Proven method for improving internal customer service. Graziadio Business Review, 3(2).

Kerns, C.D. (2010). Strengths in action behavioral checklist. Unpublished instrument.

Kerns, C.D. (2014). Fostering and managing engagement: A framework for managerial leaders. Journal of Leadership, Accountability and Ethics, 11(1), 34-49.

Kerns, C.D. (2015). Individual differences: A core leadership dimension. International Leadership Journal, 7(1), 54-77.

Kerns, C.D. (2016a). High-impact communicating: A key leadership practice. Journal of Applied Business and Economics, 18(5), 11-24.

Kerns, C.D. (2016b). Values profiling and prioritizing checklist. Unpublished instrument.

Kerns, C.D. (2017). Managing leader core values at work: A practice-oriented approach. Journal of Leadership, Accountability and Ethics, 14(1), 11-21.

Kerns, C.D. (2018). Impacting well-being at work: A key managerial leader action role. Journal of Management Policy and Practice, 19(1), 73-91.

Kerns, C.D. (2019). Leading thought leadership: A practice-oriented framework. International Leadership Journal, 11(1), 3-41.

Kozlowski, S.E.J., Watola, D.J., Jensen, J.M., Kim, B.H., \& Botero, I.C. (2009). Developing adaptive teams: A theory of dynamic team leadership. In E. Salas, G.F. Goodwin, \& C.S. Burke (Eds.), Team effectiveness in complex organizations: Cross-disciplinary perspectives and approaches (pp. 113-155). New York, NY: Psychology Press.

Kunzmann, U. \& Thomas, S. (2015). Wisdom-related knowledge across the life span. In S. Joseph (Ed.) ( $2^{\text {nd }}$ edition), Positive psychology in practice: Promoting human flourishing in work, health, education and everyday life (pp. 577-594). Hoboken, NJL John Wiley.

Locke, E.A. (2007). The case for inductive building theory building. Journal of Management, 33, 867890.

Locke, E.A., \& Cooper, C.L. (2000). Conclusion: The challenge of linking theory to practice. In C.L. Cooper \& E.A. Locke (Eds.), Industrial and organizational psychology: Linking theory with practice (pp. 335-341). Malden, MA: Blackwell.

Marks, M.A., Mathieu, J.E., \& Zaccaro, S.J. (2001). A temporally based framework and taxonomy of team processes. Academy of Management Review, 26(3), 356-376.

Mathieu, J.E., Maynard, M.T., Rapp, T.L. \& Gibson, L.L. (2008). Team effectiveness 1997-2007: A review of recent advancements and a glimpse into the future. Journal of Management, 34, 410476.

Molenberghs, P., Prochilo, G., Steffens, N.K., Zacher, H., Haslam, S.A. (2017). The neuroscience of inspirational leadership: The importance of collective-oriented language and shared group leadership. Journal of Management, 43(7), 2168-2194.

52 Journal of Leadership, Accountability and Ethics Vol. 16(1) 2019 
Morgeson, F.P., DeRue, D.S., Karam, E.P. (2010). Leadership in teams: A functional approach to understanding leadership structures and processes. Journal of Management, 36, 5-39.

Oades, L.G., \& Dulagil, A. (2017). Workplace and organizational well-being. In L.G. Oades, M.F. Steger, A.D. Fave and J. Passmore (Eds.), The wiley blackwell handbook of psychology of positivity and strengths-based approaches at work (pp. 248-271). Malden, MA: Wiley Blackwell.

Oades, L.G., Steger, M.F., Fave, A.D., \& Passmore, J. (2017). The psychology of positivity and strengths-based approaches to work. In L.G. Oades, M.F. Steger, A.D. Fave and J. Passmore (Eds.), The wiley blackwell handbook of psychology of positivity and strengths-based approaches at work (pp. 1-8). Malden, MA: Wiley Blackwell.

Ohland, M.W., Loughry, M.L., Woehr, D.J., Bullard, L.G., Felder, R.M., Finelli, C.J., Layton, R.A., Pomeranz, H.R., Schmucker, D.G. (2012). The comprehensive assessment of team member effectiveness: Development of a behaviorally anchored rating scale for self- and peer evaluation. Academy of Management Learning \& Education, 11(4), 608-630.

Peterson, C., Park, N. \& Seligman, M.E.P. (2005). Orientations to happiness and life satisfaction: The full life versus the empty life. Journal of Happiness Studies, 6(1), 25-41.

Peterson, C. \& Seligman, M.E.P. (2004). Character strengths and virtues: A handbook and classification.New York, NY: Oxford University Press.

Ragab, M.A.F., and Arisha, A. (2013). Knowledge management and measurement: A critical review. Journal of Knowledge Management, 17(6), 873-901.

Rath, T., \& Harter, J. (2010). Well-being: The five essential elements, New York, NY: Gallup Press.

Richardson, J., \& West, M. (2010). Engaged work teams. In S.L. Albrecht (Ed,), Handbook of employee engagement: Perspectives, issues, research and practice (pp. 323-340). Cheltenham, UK: Edward Elgar.

Rickards, R., Chen, M.H. \& Moger, S. (2001). Development of a self-report instrument for exploring team factor, leadership and performance relationships. British Journal of Management, Vol. 12, 243-250.

Roffey, S. (2017). Positive relationship at work. In L.G. Oades, M.F. Steger, A.D. Fave and J. Passmore (Eds.), The wiley blackwell handbook of psychology of positivity and strengths-based approaches at work (pp. 171-190).

Santos, J.P., Caetano, A. \& Tavares, S.M. (2015). Is training leaders in functional leadership a useful tool for improving the performance of leadership functions and team effectiveness? The Leadership Quarterly, Vol. 26, 470-484.

Schoemaker, P.J.H. \& Tetlock, P.E. (2017). Building a more intelligent enterprise. MIT Sloan Review, Spring 2017, 28-37.

Seligman, M.E.P. (2011). Flourish: A visionary new understanding of happiness and well-being, New York, NY: Free Press.

Shuffler, M.L., Burke, C.S., Kramer, W.S., \& Salas, E. (2013). Leading teams: Past, present and future perspectives. In M.G. Rumsey, (Ed.), The oxford handbook of leadership (pp. 144-166). New York, NY: Oxford University Press.

Tett, R.O., Guterman, H.A., Bleier, A., \& Murphy, P.J. (2000). Development and content validation of a "hyperdimensional" taxonomy of managerial competence. Human Performance, 13(3), 205-251.

Van Quaquebeke, N., \& Felps, W. (2018). Respectful Inquiry: A motivational account of leading through asking questions and listening. Academy of Management Review, 42(1), 5-27.

Walsh, R. (2015). What is wisdom? Cross-cultural and cross-disciplinary syntheses. Review of General Psychology, 19(3), 278-293.

Yukl, G. (2012). Effective leadership behavior: What we know and what questions need more attention. Academy of Management Perspective, 26(4), 66-85.

Zaccaro, S.J., Rittman, A.L., \& Marks, M.A. (2001). Team leadership. Leadership Quarterly, 12, 451483. 